\title{
Estruturas de governança e os atributos das transações entre produtores de florestas plantadas e serrarias no município de Ribas do Rio Pardo, MS, Brasil ${ }^{1}$
}

Governance structures and the attributes of transactions between producers of planted forests and sawmills in Ribas do Rio Pardo, MS, Brazil city

\section{Las estruturas de gobierno y los atributos de las transacciones entre lós productores de bosques y aserraderos plantados em El município de Ribas do Rio Pardo, MS, Brasil}

Les structures de gouvernance et les attributs des transactions entre les producteurs de la forêt et des scieries plantes dans la municipalité de Ribas do Rio Pardo, MS, Brésil

\author{
Vanessa Schmidt** \\ (vanessaschmidt89@hotmail.com) \\ Mayra Batista Bittencourt Fagundes** \\ (bitencourtmayra@gmail.com)
}

Recebido em 29/06/2013; revisado e aprovado em 30/08/2013; aceito em 09/10/2013

\begin{abstract}
Resumo: Para identificação da estrutura de governança adotada foram utilizadas as bases teóricas da Nova Economia Institucional (NEI) - Economia dos Custos de Transação (ECT). Foi realizada uma pesquisa de cunho bibliográfico e exploratório descritivo qualitativo, levantamento de informações primárias e secundárias, através da aplicação de questionários mistos semiestruturados e visitas in loco. A estrutura de governança adotada é do tipo híbrida. Palavras-chave: NEI. ECT. Silvicultura.

Abstract: To indentify the governance structure adopted it was used the theoretical foundations of New Institutional Economics (NIE) - Transaction Cost Economics (TCE). It was conducted a survey of bibliographic and descriptive exploratory nature qualitative with primary and secondary information through semi-structured mixed questionnaires and site visits. The governance structure adopted is hybrid type.

Key words: NIE. TCE. Forestry.

Resumen: Para identificar la estructura de gobierno adoptada se utilizaron las bases teóricas de la Nueva Economía Institucional (NEI) - Economia de Costos (TCE). Hemos llevado a cabo um estúdio de investigación cualitativa exploratória bibliográfico y descriptivo de información primaria y secundaria a través de cuestionarios mixtos semi-estructurados y visitas in situ. La estructura de gobierno adoptada ES do tipo híbrido.

Palabras clave: NIS. ECT. Forestal.

Résumé: Afin de déterminer la structure de gouvernance adoptées ont été utilisés la base théoriquede la nouvelle économie institutionnelle (NEI) - L-économie des coûts (TCE). Nous avons effectué um sondage auprés des bibliographique et descriptive enquête exploratoire qualitative de I'information primaire et secondaire au moyen de questionnaires et de visites sur place mixtes semi-structurés. La structure de gouvernance adopté est de type hybride. Most-clés: NIS. ECT. De la forestry.
\end{abstract}

\section{Introdução e revisão de literatura}

No Brasil, a atividade da silvicultura surge como segmento produtivo em expansão nos últimos anos, sendo que as espécies com maior destaque são o pinus e o eucalipto. Em 2011, a área de florestas plantadas no Brasil atingiu 6,5 milhões de hectares; neste total, as florestas de pinus e eucalipto tem uma participação de 73,8\%. (ABRAF, 2012). No
Mato Grosso do Sul, a produção de madeira para abastecer o sistema agroindustrial da silvicultura encontra-se em expansão. No ano de 2011, a área plantada de eucalipto e pinus atingiu um total de 475.528 hectares, garantindo ao estado $4^{\text {a }}$ colocação no ranking nacional de maiores produtores (ABRAF, 2012). Em conformidade com a tendência nacional, no Mato Grosso do Sul há uma substituição das florestas plantadas de pinus por eucalipto,

\footnotetext{
* O presente artigo faz parte do projeto de pesquisa intitulado “A eficiência e eficácia do Sistema Agroindustrial da Silvicultura no Mato Grosso do Sul a partir da visão dos agentes institucionais", com apoio da Universidade Federal de Mato Grosso do Sul, Conselho Nacional de Desenvolvimento Científico e Tecnológico e Coordenação de Aperfeiçoamento de Pessoal de Nível Superior.

** Universidade Federal de Mato Grosso do Sul (UFMS), Campo Grande, MS, Brasil.
} 
sendo que, enquanto a primeira sofreu uma redução de $8,5 \%$ entre 2009 e 2011, a segunda se expandiu $7,9 \%$ no mesmo período com bases em dados da ABRAF (2012). No Estado, $69 \%$ das terras são propícias para a silvicultura. (SEBRAE, SEPROTUR e MATO GROSSO DO SUL, 2009).

O Mato Grosso do Sul segue ainda a tendência mundial da certificação de sua cadeia de custódia, visando agregar valor aos produtos provenientes do sistema de produção agroflorestal e atender aos padrões de qualidade exigidos principalmente pelo mercado externo. Tal preocupação com as demandas de consumidores internacionais se justificam pelo crescimento da exportação de produtos florestais vivenciados pelo estado: no ano de 2011 foi constatado aumento de $28.000 \%$ na exportação de produtos florestais quand o comparado ao ano de 2001 (BRASIL, 2012). Além disso, o estado se destaca ainda na produção de madeira em tora, que para o ano de 2010 foi de 5,2 milhões de $\mathrm{m}^{3}$, o que representa um crescimento de $298,4 \%$ em relação ao ano de 2001 (IBGE, 2010b).

O sistema agroindustrial da silvicultura em territórios sul-mato-grossenses tem grande relevância em termos econômicos e sociais com destaque para o município de Ribas do Rio Pardo. Com extensão territorial de $17.308 \mathrm{~km}^{2}$ e uma população de 20.946 habitantes (IBGE, 2010a), está localizado no estado de Mato Grosso do Sul, há 102 km da capital Campo Grande. A população economicamente ativa (PEA) local correspondeu a 11.078 trabalhadores no ano de 2010 (IBGE, 2010a).

Diante do cenário produtivo do sistema florestal do estado, as serrarias da localidade surgem como importante atividade de processamento primário da madeira extraída das florestas de pinus de Ribas do Rio Pardo. No município existem 16 serrarias ativas, sendo que algumas possuem mais de uma unidade local de produção, serrando, em sua maioria, pinus, embora $95 \%$ das florestas do município sejam de eucalipto, de acordo com dados do Arranjo Produtivo Local da Madeira e Derivados de Ribas do Rio Pardo - APL de Madeira e Derivados de Ribas (2012). No município estão localizados 3 dos 5 grandes produtores de florestas do estado, de acordo com a mesma fonte.
Estima-se que, no município, haja $99 \mathrm{mil}$ hectares (ha) de florestas plantadas de acordo com dados da Federação de Agricultura e Pecuária de Mato Grosso do Sul (FAMASUL, 2012), o que responde por $20,8 \%$ das florestas plantadas do estado. Juntas, estas serrarias são responsáveis pela geração direta de 527 empregos (ano base 2012) de acordo com dados divulgados pelo APL, o que corresponde a $4,7 \%$ do total da PEA divulgada pelo IBGE (2010a) para o ano de 2010, em que foi realizado último censo.

O presente trabalho tem como objetivo identificar a estrutura de governança adotada nas transações entre os produtores de florestas plantadas e as serrarias de Ribas do Rio Pardo/MS considerando-se os atributos das transações entre estes agentes. Para tanto, o problema de pesquisa consiste em: de acordo com os atributos das transações entre os produtores de florestas plantadas e as serrarias do município de Ribas do Rio Pardo/MS, qual a estrutura de governança adotada pelos agentes? A importância acadêmica do presente trabalho se confirma na coleta de dados primários. Os resultados a serem apresentados servirão de base para o fomento de políticas públicas e privadas direcionadas ao setor.

\section{Nova Economia Institucional: Economia dos Custos de Transação (ECT)}

O primeiro insight que culminou no surgimento da NEI ocorreu com Coase em 1937 com o texto "The nature of the firm" em que as pressuposições neoclássicas começam a ser questionadas. "Yet, having regard to the fact that if production is regulated by the price movements, production could be carried on without any organization at all, well might we ask, why is there any organization?" (COASE, 1991, p. 2)

Para responder aos devidos questionamentos realizados, a NEI foi se constituindo em várias frentes teóricas de estudo. No presente trabalho, a abordagem adotada será a Economia dos Custos de Transação (ECT). "Transaction cost economics subscribe to the idea that the transaction is the basic unit of analysis and governance is an effort to craft order, thereby to mitigate conflicts and to realize mutual gains" (WILLIAMSON, 2000, p. 599).

Para WILLIAMSON (1996), os custos de transação diferem das teorias neoclássicas 
da firma e da análise tradicional de preço em algumas formas: aspectos comportamentais - oportunismo e racionalidade limitada; transação como unidade de análise; firma como estrutura de governança e não uma função de produção; direitos de propriedade difíceis de comprovar; estrutura discreta de análise e comparação com alternativas factíveis.

Os pressupostos comportamentais de racionalidade limitada e oportunismo são os primeiros aspectos a serem considerados quando da análise ou estabelecimento de algum tipo de transação entre agentes, uma vez que balizam o comportamento e as decisões a serem tomadas pelas firmas envolvidas no processo dependendo dos ganhos e perdas presentes e futuros em que os mesmos são capazes de influenciar. O oportunismo consiste no reconhecimento de que os agentes buscam o auto interesse (pressuposto neoclássico), no entanto podem fazê-lo utilizando-se de informações privilegiadas, quebrando contratos para apropriar-se de ganhos associados à transação, chegando a ferir códigos de ética aceitos pela sociedade (ZYLBERSZTAJN, 2000).

Para que o oportunismo seja considerado como pressuposto comportamental relevante para a ECT, "o comportamento humano oportunista não precisa necessariamente estar presente em todos os indivíduos, nem tampouco (...) o tempo todo. Basta a possibilidade de uma ação oportunista para que se justifique a inclusão de salvaguardas contratuais a fim de amenizar eventuais danos." (AZEVEDO, 1997, p. 79)

Já a racionalidade limitada, para ZYLBERSZTAJN (2000), decorre da complexidade do ambiente que cerca a decisão dos agentes, que não conseguem considerar todos os fatores variáveis que afetam a transação, não atingindo a racionalidade plena. “(...) All complex contracts are unavoidably incomplete. For this reason, parties will be confronted with the need to adapt to unanticipated disturbances that arise by reasons of gaps, errors and omissions in the original contract." (WILLIAMSON, 2002, p. 174) Para AZEVEDO (1997, p.42), "a inabilidade em se processar todas informações necessárias ao funcionamento de um complexo sistema de preços é um dos responsáveis por custos do uso deste sistema, ou seja, custos de transação."
Para determinar os meios através dos quais as transações econômicas irão ocorrer os agentes instituem entre si acordos, que podem se dar através de contratos, através de relações de confiança, ou mesmo através da internalização de determinadas atividades em sua firma, verticalizando-a. Ao mecanismo a ser adotado para que ocorra o processo de coordenação das atividades entre estes diferentes agentes quando de sua atuação em conjunto chama-se de estrutura de governança. Além dos pressupostos comportamentais já destacados, a decisão sobre qual a estrutura de governança mais adequada a se adotar é tomada também em função das instituições, formais ou informais, e organizações que fazem parte do processo. As instituições fazem parte do processo ditando as regras de conduta dos agentes e tendo poder, ex-post, para auxiliar na resolução de possíveis problemas gerados, enquanto as organizações além de dar representatividade aos agentes atuam na disseminação de informações, visando manter os agentes atualizados dos acontecimentos relevantes em cada setor.

Instituições são criações humanas que estruturam a interações humanas políticas, econômicas e sociais. Estas podem ser formais, incluindo constituições, leis e direitos de propriedade ou mesmo informais - tabus, costumes, cultura e tradição e, tendem a reduzir a incerteza das transações (NORTH, 1991).

A decisão da estrutura de governança a ser adotada leva em consideração, ainda, as características das transações que são realizadas entre os agentes. Isso ocorre porque a conduta dos mesmos pode variar bastante de acordo com as perspectivas que cercam os resultados presentes e futuros esperados pelos mesmos.

Os autores da ECT consideram que existem três aspectos importantes que devem ser considerados quando do estabelecimento de uma transação entre dois ou mais agentes do sistema produtivo: a frequência com que as transações acontecem ou se repetem, a especificidade dos ativos envolvidos (fator que pode tornar um agente mais ou menos vulnerável em relação à ação adotada pelos demais, envolvendo um risco de quebra de contrato) e a incerteza de mensuração ou percepção dos resultados obtidos a partir daquela transação. Para Williamson (2002, 
p.175), "given that transactions differ in their attributes and that governance structures differ in their costs and competencies, (...) transactions should be aligned with appropriate governance structures."

A alta ou baixa quantidade de vezes que determinada transação se repete pode ser decisiva na determinação da estrutura organizacional da empresa, uma vez que existem diversas possibilidades de produção e de riscos inerentes a cada uma destas escolhas. Azevedo (1997, p.89) propõe que sejam considerados três pontos com relação à frequência com que as transações ocorrem: “1) que as partes adquiram conhecimento umas das outras - o que reduz a incerteza; 2) que se construa uma reputação em torno de uma marca - o que cria uma ativo específico; 3 ) que se crie, em alguns casos, um compromisso confiável entre as partes em torno de um objetivo comum de continuidade da relação."

Para o autor, o estabelecimento de um compromisso confiável entre os agentes está diretamente associado à evitar um comportamento oportunista. "Como a transação tem a perspectiva de continuidade, uma atitude oportunista - desde que observável - tem como penalidade a interrupção da relação, cujo custo é dado pelo valor presente descontado dos ganhos futuros derivados da transação" (AZEVEDO, 1997, p. 90). Quando há uma quebra na relação de confiança estabelecida pela repetição de determinada transação passa a existir um custo mais elevado associado ao risco de comportamento oportunista por parte dos agentes.

Já quando se menciona a especificidade dos ativos, ressalta-se que quanto mais específicos forem os ativos envolvidos na transação, maiores são os incentivos para que haja um processo de verticalização. Isso se deve ao fato de que ativos específicos geram dependência e vulnerabilidade de uma ou ambas as partes.

Para Azevedo (1997, p.99), "conforme se caminha do mercado em direção à hierarquia, perde-se em incentivo e se ganha em controle. Em contrapartida, conforme se eleva a especificidade dos ativos, exige-se mais controle sobre a transação, a fim de se evitar os percalços de uma atitude oportunista." A especificidade dos ativos pode variar conforme o tipo de bem ou serviço transacionado (especificidades físicas, humanas, locacionais, ativos dedicados ou marcas), sendo os mesmos tangíveis ou intangíveis.

Já a incerteza, diferentemente da frequência das transações e da especificidade de ativos, é um aspecto de mais difícil controle, pois não pode ser mensurada. Para North (1991, p.106), "by uncertainty, I mean here a condition wherein one cannot ascertain the probability of an event and therefore cannot arrive at a way of insuring against such an occurrence."

Para tanto, considerando-se os aspectos comportamentais a que os agentes econômicos estão sujeitos - oportunismo e racionalidade limitada -, as características das transações - frequência, especificidade de ativos e incerteza - e o papel das instituições e organizações diretamente relacionadas aos agentes que irão transacionar entre si é que deve ser estabelecido o modelo de governança mais adequado para atender às necessidades dos agentes gerando os menores custos de transação possíveis.

Assim, a decisão acerca do tamanho ideal da firma e da estrutura de governança a ser adotada permeia tais aspectos propostos. O principal determinante neste sentido são os custos inerentes a cada uma destas estruturas, sejam estes os custos produtivos, logísticos ou mesmo custos de transação. Seja para contratação de outros agentes externos à firma seja para a internalização de algum processo haverá custos. Sobre isso, Coase (1991), põe que o custo de negociação e conclusão de um contrato separadamente para cada transação efetivada no mercado deve ser considerado.

Neste cenário, a NEI e, em especial, a ECT apresentam-se estritamente aplicáveis ao agronegócio. Desde sua organização de forma sistêmica, o agronegócio passou a se utilizar de ferramentas que pudessem otimizar seus processos de produção, transformação, comercialização e distribuição de bens e minimizar os custos a estes processos relacionados. Devido à perecibilidade dos produtos agropecuários, a vulnerabilidade dos agentes às oscilações dos preços nos mercados nacional e internacional e às variações climáticas, dentre outros, se faz necessário que os agente adotem mecanismos de governança com vistas a reduzir custos e riscos desnecessários, aumentar a qualidade e variabilidade dos produtos oferecidos e reduzir a sazonalidade dos ganhos advindos da atividade. 
Os mercados e consumidores tornaram-se mais complexos e exigentes, de forma que as estruturas produtivas

$\mathrm{O}$ mercado mais exigente tem feito com que os agentes se organizem para atender às novas demandas e se enquadrar no ambiente econômico mantendo ou aumentando seu nível de eficiência. O processo de certificação que vem sento adotado pelos agentes é um bom exemplo. A certificação é um processo que envolve um grupo de ações para prevenção de problemas, padronização técnica e avanços operacionais e administrativos, considerando sempre as relações com a sociedade (GIORDANO, 2009).

Por fim, para responder ao questionamento de Coase (1991), apresentado no início deste referencial teórico considera-se a proposição de Farina e Saes (1997, p. 203), "gradualmente, mesmo os produtores mais eficientes começaram a perceber que a extensão dos ajustamentos necessários para equilibrar o mercado era maior do que se podia esperar, e mesmo os mais produtivos sofriam seus efeitos adversos." Os mecanismos de preços não são capazes de, sozinhos, organizar todo o mercado da forma mais eficiente possível, motivo pelo qual os agentes se organizam.

\section{Material e métodos}

Visando atender aos objetivos propostos no presente trabalho, realizou-se uma pesquisa aplicada, de cunho bibliográfico - livros, revistas, recursos audiovisuais, publicações científicas e governamentais, teses e artigos - e exploratório qualitativo, além do levantamento de dados secundários. Além disso, foi realizada coleta de dados primários através de visita in loco, participação em reuniões do Núcleo Gestor do Arranjo Produtivo Local da Madeira e Derivados de Ribas do Rio Pardo (APL da Madeira de Ribas), visita a algumas serrarias, produtores e organizações, e conversas com especialistas para conhecimento e familiaridade dos pesquisadores.

Por fim, foram realizadas entrevistas junto a três agentes do sistema integrantes da transação, sendo 1 produtor (A) e duas serrarias $(\mathrm{B} \mathrm{e} \mathrm{C})$ que transacionam com este produtor. As entrevistas foram realizadas nos meses de janeiro e fevereiro de 2013 com aplicação de questionários mistos semiestruturados, com questões fechadas e abertas. Os contatos para aplicação de questionários foram realizados por telefone e e-mail. Os demais contatos e visitas ocorreram entre os anos de 2012 e 2013. Os agentes entrevistados foram selecionados intencionalmente, sendo que, de acordo com os especialistas consultados, estes representariam uma realidade que pode ser expandida aos demais produtores e serrarias. Considerou-se ainda que os agentes entrevistados deveriam ser certificados ou estar em processo de certificação, de forma a atender às novas demandas do mercado consumidor.

\section{Transações entre serrarias e produtores de florestas plantadas de Ribas do Rio Pardo/ MS}

O sistema florestal de Ribas do Rio Pardo é concentrado na prevalência de dois agentes principais: produtores de florestas plantadas e serrarias. Predominam as florestas de pinus e eucalipto, sendo o pinus o mais demandado pelas serrarias locais, embora pesquisas e testes para serrar madeira de eucalipto já estejam começando a ser realizadas, motivadas pela substituição das florestas de pinus pelas de eucalipto. O processamento anual de madeira serrada ultrapassa os $183.360 \mathrm{~m}^{3}$, de acordo com dados da pesquisa.

Para a realização da presente pesquisa foram entrevistados três agentes, sendo um produtor de florestas plantadas (A) e duas serrarias (B e C). As duas serrarias selecionadas transacionam com o mesmo produtor entrevistado. A decisão de realizar a pesquisa com os dois lados dos agentes envolvidos na transação (produtor e serrarias) foi motivada pelo fato de tentar perceber se ambos agentes tinham a mesma percepção acerca do mercado em que estão envolvidos e da transação que mantém entre si.

Quando da observação do perfil dos agentes pôde-se perceber que todos já estão estabelecidos no mercado há alguns anos. As serrarias B e C têm 11 e 10 anos de atuação em Ribas do Rio Pardo, respectivamente. O produtor não respondeu sobre o tempo de atuação no município, mas já está no mercado florestal desde 1971. Com relação ao tipo de madeira plantada, o produtor A diz possuir florestas de pinus e de eucalipto, de tal forma que $50 \%$ são de cada tipo, no entanto ainda 
não está comercializando a madeira de eucalipto. A é fornecedor de B e C. As serrarias serram, ambas, apenas madeira de pinus, sendo que B serra, em média, $8.400 \mathrm{~m}^{3}$ de madeira por ano e $C 30.000 \mathrm{~m}^{3}$. O produtor A vende ao ano $300.000 \mathrm{~m}^{3}$ de madeira de pinus. Assim, percebe-se que da madeira proveniente de $\mathrm{A}$ consumida por B e $\mathrm{C}$, a representatividade de participação no consumo total é de $12,8 \%$. $\mathrm{B}$ e C compram exclusivamente de A toda madeira para alimentar suas serrarias.

A partir de tais informações percebese que juntos, $B$ e $C$, representam uma fatia considerável no consumo da madeira de $\mathrm{A}$, no entanto $A$ não depende de $B$ e $C$ para vender sua madeira, pois $87,2 \%$ de sua madeira é vendida para outros clientes. Já B e C podem apresentar certa dependência de $\mathrm{A}$ em termos de fornecimento de madeira, uma vez que o tem como seus únicos fornecedores e relatam haver falta de opção em fornecimento de madeira na região.

Partindo do pressuposto de que ambas as serrarias relataram que com sua tecnologia de produção atual, após pequenos ajustes, é possível serrar madeira de eucalipto, esta possível dependência de $\mathrm{B}$ e $\mathrm{C}$ em relação a $\mathrm{A}$, se explica pelo fato de que os produtos finais originários da madeira serrada de pinus, já tem seu mercado definido e estabelecido. $\mathrm{O}$ pinus é uma madeira há muito já conhecida e bem aceita no mercado. Sobre a madeira de eucalipto ainda há incerteza de suas propriedades por parte das serrarias, estando ainda, por isso, em fase de testes. A incerteza existente permeia o fato de que não se sabe se todos os produtos finais hoje fornecidos aos consumidores (com destaque para o mercado externo, mais lucrativo) poderão continuar sendo produzidos em sua totalidade com a madeira de eucalipto, nem mesmo sabe-se qual será a aceitação dos mesmos para este tipo de madeira.

Apenas o produtor de florestas relatou participar de uma associação de produtores, a Reflore/MS, que segundo ele atua na defesa aos interesses coletivos das empresas associadas que se dedicam ao desenvolvimento e plantio de florestas. Ambos relataram ainda que não recebem apoio de nenhuma outra organização pública ou privada à realização de suas atividades. Percebe-se, assim, que para o produtor A só há uma organização relevante atuando em seu favor. Já, para as serrarias, não há atuação organizacional que as beneficie.

A baixa interação com organizações, principalmente por parte das serrarias, pode se tornar um fator negativo a partir do momento que aquelas têm a função de disseminar informações relevantes entre os agentes. Tal fato, faz com que as serrarias tenham de agir de forma individual na busca por informações com vistas a minimizar a assimetria de informação presente em todos os mercados. Outro fator a ser considerado é o fato de que a serraria $B$ faz parte do núcleo gestor do intitulado Arranjo Produtivo Local de Madeira e Derivados de Ribas do Rio Pardo, sendo este atuante, com participação frequente nas reuniões e tendo assinado um termo de cooperação técnica. Mesmo assim, durante a pesquisa a participação no APL ou mesmo no núcleo gestor não foi citada nenhuma vez. Tal fato revela indícios de que o agente não se reconhece como parte deste ou mesmo não reconhece as funções do núcleo gestor como relevantes para seu benefício.

Quando indagados sobre a participação em algum processo de certificação, os três agentes responderam positivamente, embora apenas o produtor A já tenha concluído o processo e esteja desfrutando da Certificação Florestal (CERFLOR). O produtor relatou que após o processo passou a alcançar mercados que primam por qualidade e defendem as boas práticas de manejo florestal. Já as serrarias encontram-se ambas ainda em processo de certificação, de forma que ainda não sabem quais serão os impactos percebidos após a conclusão do processo.

A certificação florestal do tipo Programa Brasileiro de Certificação Florestal (CERFLOR) (pela qual o produtor A é certificado e a serraria B encontra-se em processo de certificação) é constituída a partir de normas regulamentadas e fiscalizadas pelo Instituto Nacional de Metrologia, Normalização e Qualidade Industrial (INMETRO), representandose, então, como uma instituição formal que atua sobre estes agentes. O processo de certificação exige dos agentes dele participantes um nível padronizado de atividades desde o setor produtivo até as funções administrativas da empresa, tendo como objetivo principal estabelecer processos que garantam maior 
nível de qualidade dos produtos finais. A certificação surge ainda como um diferencial frente ao mercado, de tal forma que os agentes certificados têm acesso a mercados mais exigentes e seletivos, com produtos que respondem a determinado padrão de qualidade.

Tal necessidade é proveniente das alterações que vem ocorrendo no agronegócio, onde produtos com garantia de origem visam atender a mercados mais completos e à demanda mais exigente dos consumidores acerca das condições corretas de manejo do produto consumido. Há ainda uma alta relação entre o processo de certificação e o atendimento ao mercado externo, mais exigente do que os consumidores nacionais.

Quando indagadas sobre quais os aspectos mais importantes na compra de madeira ambas serrarias relataram a regularidade na entrega, a garantia de entrega e o preço. B relatou que a tradição ou confiança no fornecedor é fator importante e $C$ relatou a proximidade com o fornecedor. Diante disso e dos fatos anteriormente relacionados pode-se perceber que há indícios de certa especificidade nos ativos transacionados, seja pelo tipo de madeira, seja pela distância até o fornecedor. Ambos relatam que seu fornecedor está localizado há um raio médio de $80 \mathrm{~km}$ de distância, estando localizado no mesmo município, fator conveniente quando se avalia a qualidade das estradas vicinais por onde a madeira é transportada e as características da mesma. As características do produto transacionado tornam inviável seu transporte a longas distâncias. $\mathrm{O}$ transporte da madeira fica sob a responsabilidade dos caminhões da própria serraria, de tal forma que uma longa distância até o fornecedor também aumentaria o custo das mesmas.

Além disso, as serrarias B e C relatam que nas poucas vezes que tiveram problemas de não recebimento do produto na data acordada, tal fato se deu principalmente pelas condições climáticas que eram desfavoráveis. Assim, nenhuma delas recorreu judicialmente pela quebra no prazo acordado e ambas voltaram a comprar do mesmo fornecedor após este fato.

Considerando-se as condições acima citadas, embora ambas não tenham relatado o fato, percebe-se que as serrarias $B$ e $C$ percebem as instituições informais como relevantes em suas transações com o produtor. O fator confiança ou tradição do produtor está presente na confiabilidade de entrega regular da madeira, na continuidade da relação exclusiva com um mesmo fornecedor.

A frequência das transações realizadas é muito alta. Diária, de acordo com A, B e C, e as mesmas são garantidas através de contratos bianuais. Considerando-se o fato de que os contratos são de longa duração quando comparados à alta frequência com que as transações se realizam e de que o comportamento oportunista por parte do produtor é baixa, pode-se afirmar que há fortes indícios de que além das salvaguardas contratuais ambos agentes tem interesse na continuidade da relação. Além disso, as instituições informais revelam-se importantes, uma vez que problemas de quebras contratuais são raros e que quando acontecem são resolvidas entre os próprios agentes de forma pacífica.

A alta frequência das transações reduz a incerteza envolvida na transação, uma vez que as partes adquirem conhecimento umas das outras e constroem uma reputação em torno disso, estabelecendo uma relação de confiança e interesse na continuidade da relação. Apesar disso, ressalta-se que neste cenário uma atitude oportunista entre as partes poderia ser mais prejudicial se fosse tomada pelo produtor, pois as serrarias estão mais vulneráveis tendo um único fornecedor, ou seja, precisariam de um tempo para conseguir novo fornecimento, prejudicando sua produção. Apesar de perceber que há um interesse na continuidade da relação por parte de ambos, o pagamento da mercadoria adquirida pelas serrarias é sempre antecipado.

Quando indagados sobre seus maiores clientes, o produtor citou três que detêm a compra de $65 \%$ de sua produção. As serrarias B e $C$ não estavam inclusas nestes clientes. Destes, dois estão localizados no mesmo município e um no município vizinho de Água Clara, confirmando a existência de especificidade locacional também por parte do produtor. $\mathrm{O}$ produtor relata ainda que a madeira produzida por ele possui manejo específico para serraria, confirmando a especificidade do ativo transacionado. Do total de sua produção, $80 \%$ é destinado às serrarias e $20 \%$ para carvão.

Para o produtor a relação de confiança não foi mencionada, mas nas transações com 
B e C, se mostra aparente conforme já relatado acima. Para o produtor, não são predominantes as vendas via contrato. Com relação aos fatores mais importantes quando da venda da madeira, houve um consenso com as serrarias, sendo que qualidade e regularidade na entrega foram citados. Para A, B e C a qualidade da madeira ofertada no mercado é uma constante, no entanto para A haja poucos fornecedores deste tipo de madeira. Quando questionados sobre a realização de outros tipos de atividades, A e B disseram não realizar nenhuma outra atividade, enquanto C disse realizar também operações de compra e venda de madeira serrada. Tal fato torna-se importante a partir do momento que a realização de um único tipo de atividade dá menos opções estratégicas dos agentes perante alterações no mercado.

Constata-se que apesar de A ser menos vulnerável a uma atitude oportunista por parte de $B$ e $C$, uma vez que pode comercializar sua madeira com outras serrarias, A ainda assim está limitado a vender $80 \%$ de sua produção para serrarias que estejam localizadas em Ribas do Rio Pardo ou municípios vizinhos, o que explica o não interesse por quebras contratuais. Ambos agentes ficam reféns da transação, embora A menos que B e C. Por fim, quando indagados sobre diferenciação de preços, ambas as partes relataram que a mesma ocorre apenas em função da qualidade da madeira transacionada, que de acordo com os entrevistados possui baixa variabilidade.

Com base nas características dos agentes e sua percepção com relação às instituições e organizações, as características da transação e os pressupostos comportamentais, identificou-se que a estrutura de governança adotada pelos agentes é do tipo híbrido, com relações contratuais de médio prazo estabelecidas entre os agentes, além da existência de relação de confiança e tradição.

\section{Conclusão}

A partir da realização da presente pesquisa foi possível perceber que a estrutura de governança adotada pelos agentes de Ribas do Rio Pardo (serrarias e produtores) é determinada pelas características das transações, pelos pressupostos comportamentais dos agentes e pela presença de instituições e organizações. No caso estudado, foi detectada a presença de instituições formais e informais na transação. Percebeu-se ainda que, embora haja instituições informais influenciando na relação, nem sempre os agentes tiveram esta clara percepção. Ademais, a organização presente e citada como relevante atua apenas na defesa dos interesses coletivos dos produtores, não tendo sido percebida grande influência da mesma sobre as transações com as serrarias em específico.

Já com relação aos pressupostos comportamentais foi detectada a presença de racionalidade limitada, no entanto os problemas ocorrem com pouca frequência e quando ocorrem são resolvidos pacificamente entre os próprios agentes. $\mathrm{O}$ oportunismo não foi detectado nas relações até o presente momento por nenhuma das partes, mas deve ser sempre considerado como uma possibilidade. Percebeu-se certa dependência entre os agentes. Mais dependência por parte das serrarias do que por parte dos produtores, no entanto ambos têm interesse na continuidade da relação. Há uma reputação construída e certa relação de confiança, principalmente no produtor.

Com relação às características das transações, detectou-se alta frequência, média especificidade de ativos (especificidade do produto transacionado e especificidade locacional) e baixa incerteza. Considerando-se todas estas variáveis, a estrutura de governança adotada pelos agentes é a estrutura híbrida, garantida por contratos e relação de confiança/ reputação.

Frente à alteração mercadológica que vem acontecendo de substituição de pinus por eucalipto, embora as serrarias já venham pesquisando o novo tipo de madeira e sua aplicabilidade, ainda é incerta sua aceitação de mercado, seus produtos finais e seu valor agregado. Por parte do produtor, já vêm sendo realizado o plantio de eucalipto, visando atender à esta nova tendência, mas a maturidade das florestas para venda ainda não foi atingida. Tais fatos geram certa incerteza que permeia o futuro da cadeia produtiva. Tanto produtores quanto serrarias ainda veem tal questão como um problema futuro e continuam suas atividades normalmente enquanto há pinus plantado para alimentar as serrarias.

Percebe-se aí a importância de que tanto produtores quanto serrarias passem a olhar $\mathrm{o}$ 

plantadas e serrarias no município de Ribas do Rio Pardo, MS, Brasil

problema como algo mais próximo a eles, buscando uma maior variabilidade de produtos e mercados com boa aceitação para que sua lucratividade não caia de forma irreversível. O mesmo vale para os produtores, uma vez que o eucalipto apresenta manejo específico para cada destinação (carvão, serraria, papel e celulose, energia, dentre outros). Neste aspecto o planejamento futuro e a instituição de ações estratégicas e pesquisa de mercado são relevantes. Tendo em vista que o presente trabalho foi realizado com poucos agentes, como proposta de trabalho futuro será realizada uma pesquisa com todos os produtores de pinus e eucalipto e todas as serrarias presentes no município de Ribas do Rio Pardo/MS, tendo como objetivo verificar se a estrutura de governança encontrada se aplica também aos demais agentes ou se é limitada aos aqui relacionados.

\section{Referências}

ABRAF. Anuário Estatístico da ABRAF 2012 ano base 2011.. Brasília: Associação Brasileira de Produtores de Florestas Plantadas, 2012. p. 150.

AZEVEDO, P. F. Antecedentes - Coase e os anos 30: o redirecionamento do enfoque. In: FARINA, E. M. M. Q.; AZEVEDO, P. F.; SAES, M. S. M. Competitividade: Mercado, Estado e Organizações. São Paulo: Singular, 1997. p. 286. (Cap. Parte I).

ARRANJO PRODUTIVO LOCAL DE MADEIRA E DERIVADOS DE RIBAS DO RIO PARDO. APL de Madeira e Derivados de Ribas. Núcleo Gestor. Reunião núcleo gestor, 2012.

BRASIL. Ministério da Agricultura, Pecuária e Abastecimento (MAPA). Agrostat, 2012. Disponivel em: <http:/ / sistemasweb.agricultura.gov.br/pages/AGROSTAT. html>. Acesso em: 15 jan. 2013.
COASE, R. H. The Nature of the Firm. In: WILLIAMSON, O.; WINTER, S. G. The nature of the firm. New York: Oxford Univesity Press, 1991. p. 17.

Federação da Agricultura e Pecuária de Mato Grosso do Sul (FAMASUL). Projeto Siga - Mapa de Área Plantada no MS, 2012.

FARINA, E. M. M. Q.; SAES, M. S. M. Os Desafios do Livre Mercado. In: FARINA, E. M. M. Q.; AZEVEDO, P. F.; SAES, M. S. M. Competitividade: Mercado, Estado e Organizações. São Paulo: Singular, 1997. p. 195-232. (Cap. 7).

GIORDANO, S. R. The Importance of Socioenvironmental Certification in Agri-Chains. In: ZULBERSZTAJN, D.; OMTA, O. Advances in Supply Chaibn Analysys in Agri-Food Systems. São Paulo: Singular, 2009. p. 167-185.

Instituto Brasileiro de Geografia e Estatística (IBGE). IBGE Cidades, 2010a. Disponivel em: <http://www. ibge.gov.br/cidadesat/topwindow.htm?1>. Acesso em: 08 fev. 2013.

Instituto Brasileiro de Geografia e Estatística (IBGE). SIDRA, 2010b. Disponivel em: <http://www.sidra. ibge.gov.br/bda/silvi/default.asp? $z=t \& o=29 \& i=P>$. Acesso em: 18 set. 2012.

NORTH, D. C. Institutions. The Journal of Economic Perspectives, v. 5; n. 1, p. 97-112, 1991.

SEBRAE; SEPROTUR; MATO GROSSO DO SUL. Plano Estadual para o Desenvolvimento Sustentável de Florestas Plantadas - Relatório Final. Campo Grande: Governo do Estado de Mato Grosso do Sul; Serviço Brasileiro de Apoio às Micro e Pequenas Empresas; Secretaria de Estado de Desenvolvimento Agrário de Produção, da Indústria, do Comércio e do Turismo. 2009p. 451..

WILLIAMSON, E. The nem institutional economics: taking stock, looking ahead. Journal of Economic Literature, v. 38, p. 595-613, Set. 2000.

WILLIAMSON, O. E. The Mechanisms of Governance. New York: Oxford University Press, 1996.

WILLIAMSON, O. E. The Theory os the Firm as Governance Structure: from Choice to Contract. Journal of Economic Perspectives, Summer 2002. 171 - 195.

ZYLBERSZTAJN, D. Economia das Organizações. In: ZYLBERSZTAJN, D.; NEVES, F. N. Gestão dos Negócios Agroalimentares. São Paulo: Pioneira, 2000. p. 23-38. 
